\title{
Instituições para Fomentar a Integração do Setor Elétrico na América do Sul
}

\section{Institutions for Promoting the Electric Sector Integration of South America}

\author{
DOI: $10.21530 /$ ci.v13n1.2018.717
}

\author{
João Manoel Losada Moreira ${ }^{1}$ \\ Roberto Tadeu Soares Pinto ${ }^{2}$
}

\section{Resumo}

Este trabalho busca identificar e discutir um conjunto de instituições e arenas que possam fomentar a integração do setor elétrico na América do Sul por meio de agentes de mercado. Para operacionalizar a geração e comercialização de eletricidade foram identificadas 4 arenas e 5 organizações para acomodar os diferentes interesses e atividades dos agentes econômicos, stakeholders e agentes dos vários países. O processo poderia iniciar por meio da integração entre o Brasil e países vizinhos e se basear em energias renováveis e sustentáveis para evitar a exaustão de recursos energéticos. Seriam construídas conexões e linhas de transmissão nas fronteiras e os mercados conectados de ambos os lados da fronteira seriam vistos como extensões dos respectivos sistemas nacionais. A implementação de tal arquitetura institucional requer liderança e envolve custos. O Brasil deveria considerar liderar esse processo e atuar como um paymaster parcial para iniciar relações bilaterais de importação e exportação de eletricidade dos e para os países vizinhos.

Palavras-chave: Integração Sul-Americana; Eletricidade; Mercado; Instituições.

1 Graduado em física (1977) pela Universidade de Brasília, DF, mestre (1982) e doutor (1984) em engenharia nuclear pela University of Michigan, Ann Arbor, EUA. É professor titular em energia no Centro de Engenharia, Modelagem e Ciências Sociais Aplicadas da Universidade Federal do ABC.

2 Graduado em engenharia elétrica (1996) pela Faculdade de Engenharia São Paulo e mestre em energia (2017) pela Universidade Federal do ABC. É professor de pós-graduação na Faculdade de Tecnologia SENAI Mariano Ferraz, FATEC SENAI, São Paulo, SP.

Agradeço à Coordenação de Aperfeiçoamento de Pessoal de Nível Superior (CAPES) pelo apoio fornecido durante a realização da pesquisa.

Artigo submetido em 01/10/2017 e aprovado em 13/03/2018. 


\section{Abstract}

This work seeks to identify and discuss a set of institutions and arenas that can foster the integration of the electric sector in South America through market agents. To make possible the generation and commercialization of electricity, we identified 4 arenas and 5 organizations to accommodate different interests and activities of the economic agents, stakeholders and agents of the various countries. The process could begin by integrating Brazil and neighboring countries and building on sustainable and renewable energy to avoid depletion of energy resources. Connections and transmission lines would be built at the borders and the connected markets on both sides would be seen as extensions of the respective national electricity systems. Implementing such an institutional architecture requires leadership and involves costs. Brazil should consider leading this process and acting as a partial paymaster to initiate bilateral relations to import and export electricity from and to the neighboring countries.

Keywords: South American Integration; Electricity; Market; Institutions.

\section{Introdução}

A partir de 1980, o esforço de integração da América do Sul foi intenso e envolveu vários setores, inclusive o de infraestrutura ligado à energia elétrica. Um conjunto de instituições e um sistema de governança foram implantados no continente sul-americano de forma a poder se falar que a integração é um processo contemplado por todos os países envolvidos (CARVALHO; GONÇALVES, 2016; DESIDERÁ NETO et al., 2014; MARIANO, 2014; PADULA, 2014; SARAIVA, 2013; SPEKTOR, 2010; TEIXEIRA, 2014). Inicialmente, as questões sobre como incrementar as trocas comerciais entre os países do continente dominaram a agenda do processo de integração por meio de acordos entre grupos de países como o Mercado Comum do Sul (MERCOSUL) e a Aliança do Pacifico. A partir de acordos entre governos via reuniões de chefes de Estado e de ministros das relações exteriores, o processo de integração comercial exigiu e evoluiu para a criação de órgãos especializados para resolver questões específicas à medida que o nível de intercâmbio comercial aumentava e se diversificava. Em relação à área de infraestrutura de energia, não se atingiu ainda tal evolução. Contudo já se estabeleceu o Conselho de Infraestrutura e Planejamento da UNASUL (COSIPLAN) como principal foro de alto nível para a condução do processo de integração da infraestrutura da América do Sul.

A integração do setor de energia elétrica é bem distinta da integração comercial, pois depende fortemente de características específicas de cada um dos sistemas 
e da estrutura econômica dos diversos países. O setor elétrico tem características peculiares por ser uma indústria intensiva de capital e de rede. Ela utiliza um conjunto de infraestrutura distribuída por largos espaços geográficos para conectar a geração de energia, geralmente localizada em algumas regiões, e transmiti-la para os diversos centros de consumo (HALLACK, 2014; MAYO, 2012). Por ser intensiva em capital, ela exige prazos de amortização dos investimentos que podem atingir algumas décadas. Para ser eficaz e eficiente, a integração sul-americana do setor elétrico se estenderia pelo território de vários países e exigiria a compatibilização regulatória entre eles durante décadas.

Tomando como base teórica a integração regional vista como um processo dinâmico que intensifica as relações entre agentes regionais visando a criação de novas formas de relacionamento e governança, encontramos dois aspectos importantes que merecem atenção: a) os Estados autônomos se reúnem em prol de alguns objetivos considerados importantes e que dificilmente poderiam ser conseguidos atuando individualmente e b) os Estados são diferentes e apresentam peculiaridades, interesses nacionais particulares e diferentes condições socioeconômicas (PADULA, 2014). Consequentemente, a forma de organização e o papel das instituições devem ser tais que os agentes participantes dos vários países tenham uma conduta aceita por todos, possam satisfazer suas necessidades e respondam às demandas apresentadas pela coletividade.

Em geral, há consenso que há vantagens no processo de integração, entretanto dificuldades específicas impedem ou paralisam o seu andamento. As principais barreiras identificadas nos vários estudos incluem perda de autonomia nacional, assimetrias entre os países, perda de capacidade de planejamento, perda de segurança energética, esgotamento das reservas nacionais, dificuldades de atração de investimentos nacionais e internacionais, dificuldades de modernização e ganhos de tecnologia e competitividade e falta de maturidade institucional dos países sul-americanos (CARVALHO; GONÇALVES, 2016; DESIDERÁ NETO et al., 2014; MARIANO, 2014; PADULA, 2014; SARAIVA, 2013; SPEKTOR, 2010; TEIXEIRA, 2014; PINTO, 2017). A arquitetura ou estrutura de instituições adequadas para executar as complexas ações de geração, transmissão e comercialização de energia elétrica entre os países deve levar em conta tais barreiras (DESIDERÁ NETO et al., 2014; MARIANO, 2014; PADULA, 2014; SOARES; MOREIRA, 2012; MOREIRA; PINTO, 2013; SCHERMA, 2016; SPEKTOR, 2010; TEIXEIRA, 2014).

Atualmente, o intercâmbio de energia entre os países da região é muito pequeno e não importante para os diversos países, com a exceção dos acordos 
específicos do Paraguai com o Brasil e com a Argentina (PINTO, 2017). Para incrementar o intercâmbio de energia elétrica entre os países do continente, seria necessária a criação de alguma estrutura institucional internacional para tratar das atividades cotidianas do setor, pois a relação entre governos nos níveis ministeriais é insuficiente (SPEKTOR, 2010). Necessita-se de um corpo burocrático para realizar as atividades de integração física, despacho de energia, comercial e principalmente para a solução de conflitos das relações operacionais cotidianas (HALLACK, 2014; DESIDERÁ NETO et al., 2014).

As relações entre países ocorrem por meio de instituições nacionais, como os ministérios de relações exteriores, e várias instituições internacionais. No caso da integração do setor elétrico de alguns países da América do Sul, uma base institucional mínima deveria ser construída para promover sua governança e gerar resultados para esses países que, dificilmente, poderiam ser conseguidos quando atuando individualmente (HERZ; HOFFMANN; TABAK, 2015a; CAF, 2016; PADULA, 2014).

Este trabalho baseia-se no argumento de que a comercialização de energia segundo uma estrutura de mercado entre os países da América do Sul, a partir de uma arquitetura adequada de instituições, pode contribuir de forma efetiva para a resolução de problemas e dificuldades dos sistemas nacionais. Este trabalho tem como objetivo principal contribuir para a discussão da integração do setor de energia elétrica da América do Sul com foco no aumento da comercialização de energia entre os países da região. Ao longo do artigo, buscamos identificar que formas de energia seriam mais adequadas incluir em um processo de integração regional, identificar um conjunto de arenas e agentes econômicos e sociais envolvidos no setor de energia transfronteiriço e discutir uma possível arquitetura de instituições para viabilizar esse tipo de integração do setor elétrico na América do Sul.

Embora o foco deste trabalho seja o Brasil, buscamos discutir que tipos de instituições e arquitetura de governança seriam necessários para obter benefícios simétricos aos países envolvidos, caso contrário, dificilmente ocorrerá um processo de integração do setor elétrico da América do Sul. Nesse sentido, é levado em conta o estado atual do processo de integração na América do Sul e também aspectos técnicos, econômicos, de sustentabilidade, diplomáticos e aspectos particulares ao setor de energia elétrica. 


\section{Metodologia}

A base teórica de relações internacionais adotada neste trabalho é a da integração regional por meio do estabelecimento de regras e normas (regimes internacionais) para uma área econômica específica: o setor elétrico na região sul-americana (HERZ; HOFFMANN; TABAK, 2015a, 2015b). Busca-se conseguir tal feito por meio de novas formas de governança e instituições para operar o setor elétrico no espaço regional sul-americano. Adota-se a governança do ponto de vista diplomático reconhecendo a importância dos governos de Estados nacionais nas várias arenas dos setores diplomáticos e de eletricidade (GONÇALVES, 2006; HERZ; HOFFMANN; TABAK, 2015c). Esses se reuniriam e procurariam consensualmente atingir o objetivo de construir um conjunto de mecanismos e instituições que permitam a integração e operacionalização do intercâmbio de energia elétrica entre os países de forma tal que possa ser considerada positiva pelos vários stakeholders dos vários países envolvidos. Antes de continuar, faz-se necessário definir alguns termos para facilitar a compreensão do trabalho:

- Governança - é o conjunto de processos, regulamentos, formas de tomada de decisão e ideias que mostram a maneira pela qual uma organização, empresa, setores do Estado, Estados ou conjunto de Estados são dirigidos ou administrados. Há vários tipos de governança: corporativa, global, diplomática etc.;

- Instituição - é o conjunto de organizações, normas e procedimentos formais e culturais (normas e procedimentos informais);

- Agente - é um ator que interage em alguma arena do âmbito nacional ou internacional. Pode ser uma empresa, um indivíduo, uma organização não governamental nacional ou internacional, atores subnacionais, bancos de investimentos, agências reguladoras, prefeituras etc.;

- Arena - local físico ou fictício onde os atores ou agentes interagem para realizar alguma ação ou deliberação;

- Arquitetura - estrutura ou forma de um setor, no caso em estudo, do setor de energia elétrica de dois ou mais países sul-americanos com todas as relações entre seus agentes;

- Segurança energética - é um termo utilizado de forma ampla podendo abarcar várias questões, contudo, neste trabalho, a segurança energética se restringe à garantia de suprimento de eletricidade e à certeza de fornecimento de energia elétrica previamente acertada por meio de um acordo entre países. 
- Stakeholders - pessoas, grupos ou instituições interessados de alguma forma nas questões envolvidas.

A Figura 1a apresenta uma representação possível de arena e agentes. Qualquer local ou situação de interação entre os agentes é denominada arena. Essa pode ser de compra e venda de energia, decisão de investimentos para expansão do sistema, conflitos diplomáticos etc. Na arena, interagem os vários agentes, organizações e a sociedade.

O agente pode interagir também com várias arenas e essas estão interligadas porque vários agentes atuam em várias delas. A Figura 1b exemplifica tal situação onde um agente interage com 4 diferentes arenas interconectadas. No caso da integração do setor elétrico de dois países da América do Sul, essas arenas podem representar a comercialização de energia (compra e venda), uma instituição para dirimir conflitos, uma arena de planejamento da expansão da capacidade instalada com novos projetos ou a reunião de ministros de Estado programada para ocorrer semestralmente.

Para estabelecer os principais elementos de uma arquitetura de instituições para viabilizar um maior intercâmbio de energia elétrica entre os países da América do Sul, segundo uma estrutura de mercado, vamos realizar os seguintes passos:

- Identificar os stakeholders e agentes importantes do setor de energia elétrica continental, as arenas necessárias para viabilizar os processos de mercados integrados do setor de energia elétrica. Para identificar arenas e agentes serão observadas aquelas existentes na América Central, União Europeia e no Brasil (POLLITT; MARSILIU, 2016; BALAGUER, 2011; CASTRO, 2015; CEPAL, 2016; CIER, 2016);

- Delinear a arquitetura de instituições que seriam necessárias para viabilizar a governança do setor elétrico da América do Sul, enfatizando a comercialização de energia elétrica;

- Discutir a adequação da proposta de arquitetura de instituições vis-à-vis às barreiras citadas na introdução. 
Figura 1. Estrutura de arena e agentes interagindo em arenas

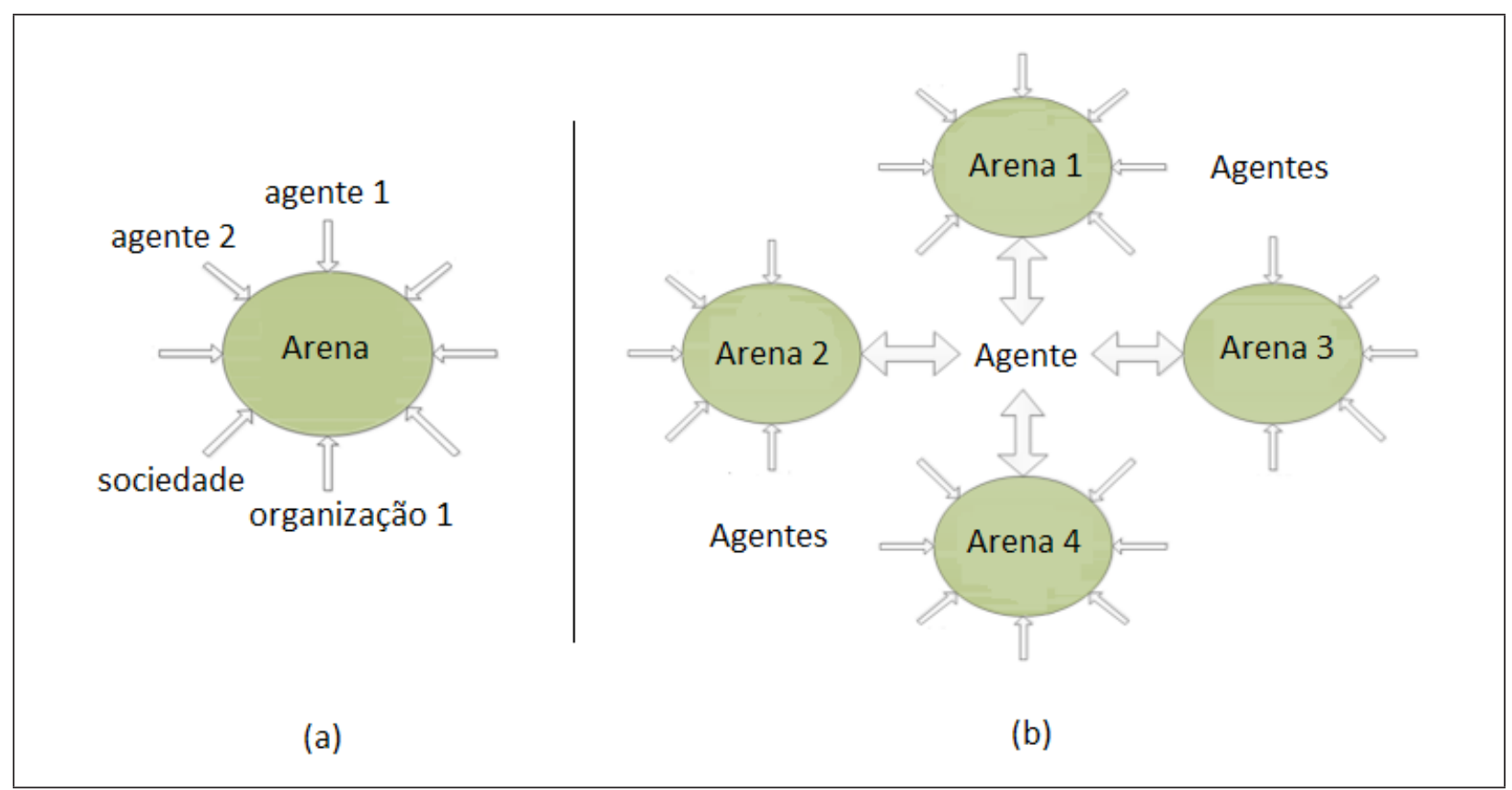

Fonte: Autoria própria.

\section{Stakeholders, agentes e arenas relevantes para a integração do setor de energia elétrica na América do Sul}

Em um processo de integração do setor elétrico entre países, um agente econômico pode ser uma empresa geradora de energia, produtor independente, distribuidor de energia, comercializador de energia, consumidor de energia, etc. Esse agente interage com um conjunto de outros agentes, instituições e stakeholders em diversas situações, condições ou locais. Esses stakeholders podem ser agentes econômicos, participantes da sociedade organizada, como governos, prefeituras, associações ou segmentos da sociedade e investidores públicos ou privados, bancos, agências de fomento etc. As interações são complexas e multifacetadas, mas, para encaminhar a discussão para o objetivo desse trabalho, foram divididas em quatro arenas principais (PINTO, 2017; MARIANO, 2014; PADULA, 2014; SOARES; MOREIRA, 2012; MOREIRA; PINTO, 2013; SPEKTOR, 2010; TEIXEIRA, 2014):

a) Arena de fornecimento de energia - onde se realizam as operações de compra e venda de energia;

b) Arena de planejamento da operação do sistema elétrico - onde se define como será o despacho de energia elétrica;

c) Arena de planejamento da expansão do sistema - onde se viabilizam novos investimentos e crescimento do sistema; 
d) Arena de regulação, fiscalização e de resolução de conflitos - onde as regras são estabelecidas, verificadas e conflitos são resolvidos.

O agente econômico, seja ele um produtor independente ou um consumidor industrial, interagirá com esse sistema de arenas ao longo de suas atividades econômicas.

Deve-se salientar que as arenas de planejamento de operação e de fornecimento de energia no Brasil são muito interligadas, pois o despacho das unidades geradoras leva em conta o planejamento centralizado do Operador Nacional do Sistema Elétrico (ONS), que busca garantir segurança de fornecimento, modicidade tarifária e outros objetivos, e contratos de compra e venda de energia elétrica entre os vários agentes econômicos. O despacho de energia ocorre a partir de sinais do mercado de energia elétrica oriundos da arena de fornecimento de energia e também de comandos administrativos oriundos da arena de planejamento de operação.

No Brasil, a arena de expansão do sistema elétrico também é centralizada e administrada. A Empresa de Pesquisa Energética (EPE) atua para a expansão do sistema a partir de sinais de mercado, do operador nacional do sistema, ONS, investidores e de uma série de outros interessados. Diversos representantes da sociedade estão presentes em todas as arenas, levando para as discussões questões socioambientais locais, nacionais e globais, reivindicações de estados e municípios etc. As questões podem envolver tarifas elevadas - que são discutidas na arena de fornecimento de energia; licenciamento de um novo projeto - discutido na arena de expansão do sistema; ou restrições quanto a emissões e danos à saúde da população - discutidas na arena de regulação, fiscalização e conflitos.

A Figura 2 mostra o sistema interligado brasileiro na condição vigente em 2015. Sua estrutura atual evoluiu a partir de subsistemas regionais em um processo contínuo de integração ao longo do tempo. Os subsistemas das várias regiões foram sendo interligados gradativamente por linhas de transmissão, como pode ser visto na Figura 2. Inicialmente os subsistemas das regiões Sudeste, Centro-Oeste e Sul operavam com pouca integração. Posteriormente operou-se a integração dos subsistemas Sudeste e Centro-Oeste de forma intensa e, a seguir, com o subsistema do Sul. Mais recentemente, o subsistema do Nordeste foi integrado aos subsistemas Sudeste e Centro-Oeste e também ao subsistema Norte. Estima-se que a integração dos subsistemas brasileiros permitiu uma economia de $20 \%$ em investimentos (ONS, 2016). 
A Figura 2 mostra também conexões entre o Brasil, Paraguai, Uruguai e Argentina e o crescimento do sistema elétrico brasileiro em direção às regiões fronteiriças com a Bolívia, Peru e Venezuela.

Há basicamente dois tipos de organizações internacionais que devem existir para conduzir a integração do setor elétrico de dois ou mais países: organizações mais diretamente ligadas às questões diplomáticas, como os blocos econômicos Comunidade Andina (CAN), Comunidade dos Estados Latino-Americanos e Caribenhos (CELAC), MERCOSUL e União das Nações Sul-Americanas (UNASUL); e organizações de caráter técnico, econômico e operacional para tocar o dia a dia do intercâmbio de energia, promover novos investimentos ou resolver disputas. Do ponto de vista operacional, tais organizações e aquelas a serem construídas (principalmente as do segundo tipo citado acima) devem ser capazes de contornar as barreiras apresentadas na introdução deste trabalho.

\section{Figura 2. Sistema Interligado Nacional do Brasil em 2015}

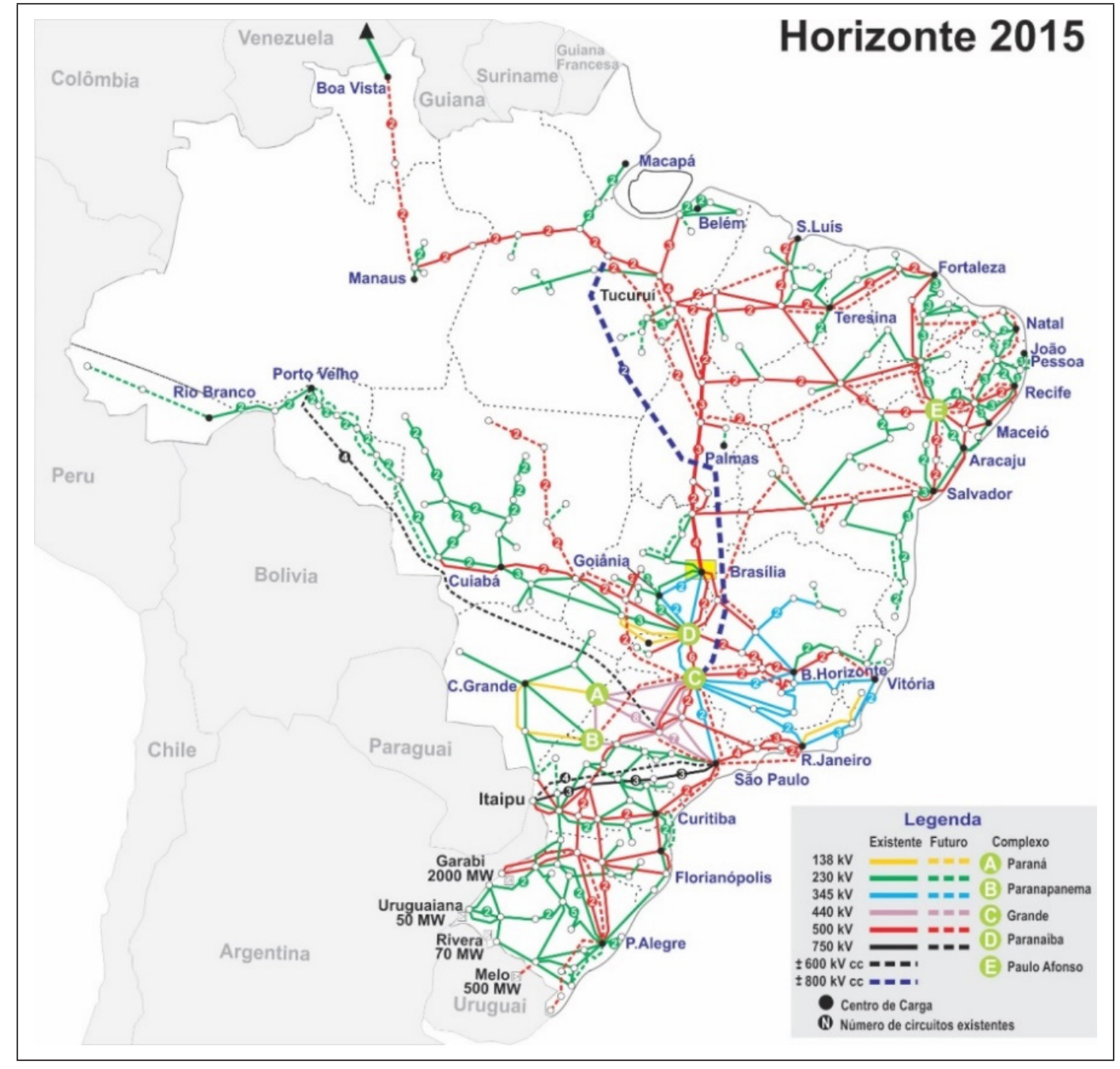

Fonte: ONS, 2016. 


\section{Situação atual da energia elétrica na América do Sul}

A disponibilidade de energia elétrica está vinculada às características da matriz energética de cada país, ou seja, aos seus recursos de energia primária para conversão e geração de eletricidade. A América do Sul possui uma abundância em recursos naturais renováveis e não renováveis. Tais condições possibilitam a utilização de diferentes fontes (eólica, hidráulica, solar, térmica e outros) para geração de eletricidade (PSR, 2012; CIER, 2013).

Nas últimas décadas, novas tecnologias de geração foram desenvolvidas buscando alternativas à utilização de combustíveis fósseis para a geração de eletricidade. Restringindo às fontes renováveis e de maior sustentabilidade, hídricas e eólicas (MOREIRA et al., 2015), a Tabela 1 mostra em termos globais o potencial de geração de eletricidade no continente sul-americano ainda por ser explorado. O potencial hidrelétrico total é de $552 \mathrm{GW}$, aproximadamente $21 \%$ já foi explorado e restariam para serem aproveitados 436 GW. O potencial eólico é de aproximadamente $300 \mathrm{GW}$ e é praticamente inexplorado. O potencial eólico da região pode ser superior ao valor apresentado na Tabela 1, pois as estimativas estão sendo revisadas em alguns países e em outros sequer estão disponíveis (PSR, 2012).

Tabela 1. Potencial de geração elétrica disponível na América do Sul a partir das fontes renováveis hidráulica e eólica

\begin{tabular}{lcc}
\hline \multicolumn{1}{c}{ País } & $\begin{array}{c}\text { Potencial Hídrico } \\
(\mathbf{G W})\end{array}$ & $\begin{array}{c}\text { Potencial Eólico } \\
(\mathbf{G W})\end{array}$ \\
\hline Argentina & 44 & 10 \\
Bolívia & 39 & - \\
Brasil & 144 & 300 \\
Chile & 26 & 5 \\
Colômbia & 93 & 20 \\
Peru & 62 & 10 \\
Venezuela & 28 & $\mathbf{3 4 5}$ \\
\hline Total & $\mathbf{4 3 6}$ & $\left(\mathrm{f}_{\mathrm{c}}=0,27\right) 93 \mathrm{GW}$ \\
\hline Total aproximado de potência disponível* & $\left(\mathrm{f}_{\mathrm{c}}=0,5\right) 218 \mathrm{GW}$ & \\
Total (hidro + eólica) $=781$ GW & & \\
Total de potência firme (hidro + eólica) $311 \mathrm{GW}$ & & \\
* Valor aproximado levando em conta a sazonalidade da geração hidráulica e a intermitência da geração eólica; $\mathrm{f}_{\mathrm{c}}$ é \\
o fator de capacidade da fonte de energia. \\
Fonte: PSR, 2012; CAF, 2016.
\end{tabular}


A evolução da eletricidade gerada na América do Sul no período de 1990 a 2014 é apresentada na Figura 3. A ordenada está em escala logarítmica para permitir uma melhor comparação da taxa de crescimento anual nos diversos países. Esses valores são relevantes. Por exemplo, a energia elétrica consumida pelo Brasil em 2014 (518 TWh) é comparável à consumida pela Alemanha (533 TWh) e superiores àquelas consumidas pelas França (431 TWh) e Reino Unido (309 TWh) (EIA, 2016). A capacidade instalada e a energia gerada no Brasil é cerca de $50 \%$ do total do continente.

A disponibilidade de recursos energéticos renováveis e sustentáveis para a comercialização no continente é um fator favorável à integração, pois reduz o risco de exaustão de recursos energéticos no futuro. Outro ponto favorável é que os vários países, embora apresentem assimetrias econômicas evidentes, também apresentam taxas de crescimento para a geração de energia semelhante.

\section{Figura 3. Evolução da eletricidade gerada nos vários países da América do Sul}

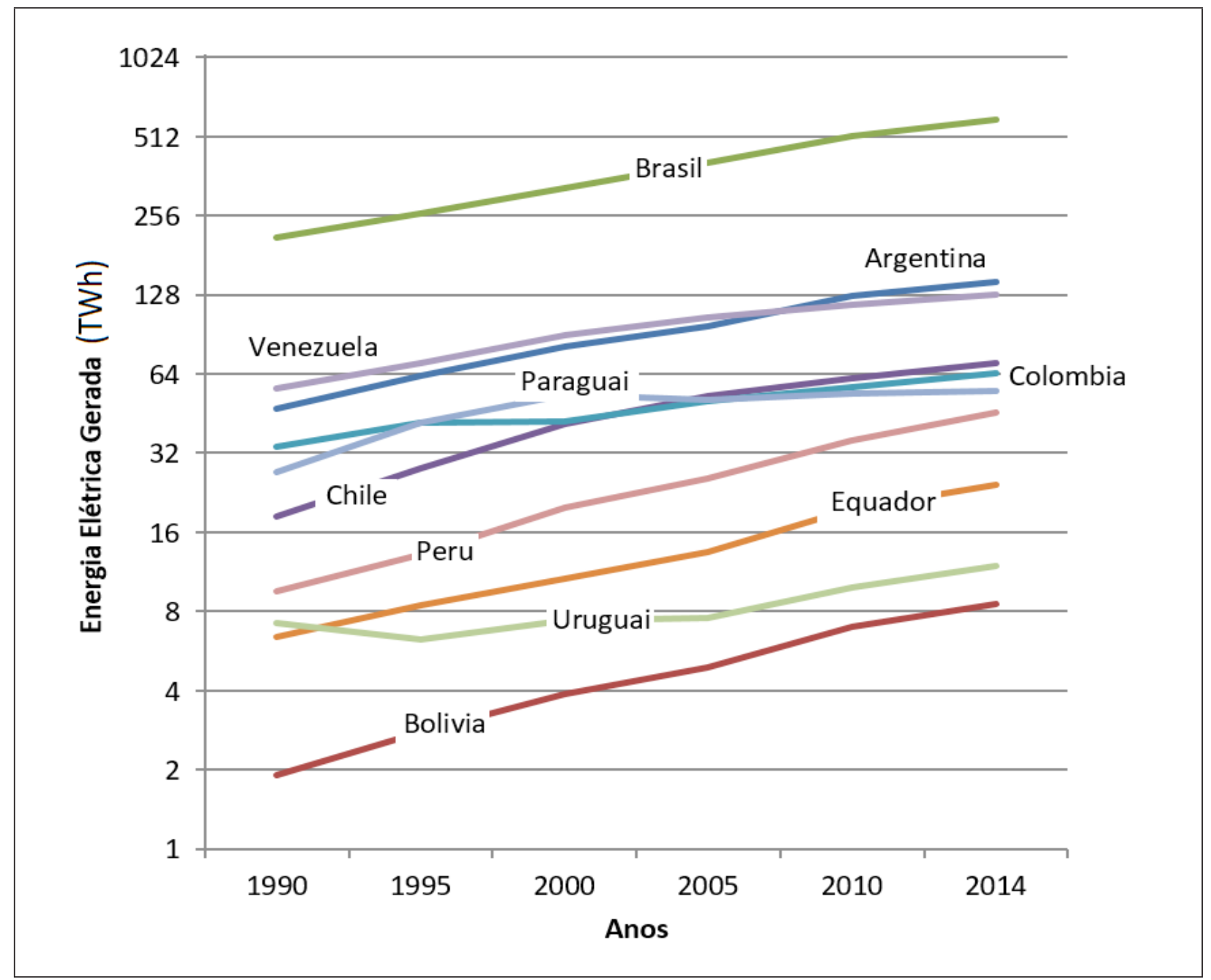

Fonte: CIER, 2013. 
Para comercialização e intercâmbio de eletricidade, é necessário haver pontos de interconexão das redes elétricas entre os vários países. O Brasil, de acordo com o ONS - Operador Nacional do Sistema (ONS, 2012), encontra-se interligado aos sistemas elétricos da Argentina, Uruguai e Paraguai, por meio de subestações especificas para tal finalidade, visando à contabilização dos fluxos de energia entre os países.

A Figura 4 possibilita uma visão espacial das conexões internacionais e dos projetos binacionais do setor elétrico da América do Sul. Observam-se as dimensões continentais da região, bem como as condições de fronteira. Excluindo-se a interconexão com a Venezuela, não existem outras interconexões internacionais do Brasil nas regiões norte e centro-oeste. O intercâmbio de energia com a Venezuela, Paraguai, Argentina e Uruguai ocorre por meio de acordos binacionais definidos com regras próprias estabelecidas entre governos.

Figura 4. Interligações internacionais em alta tensão e projetos binacionais

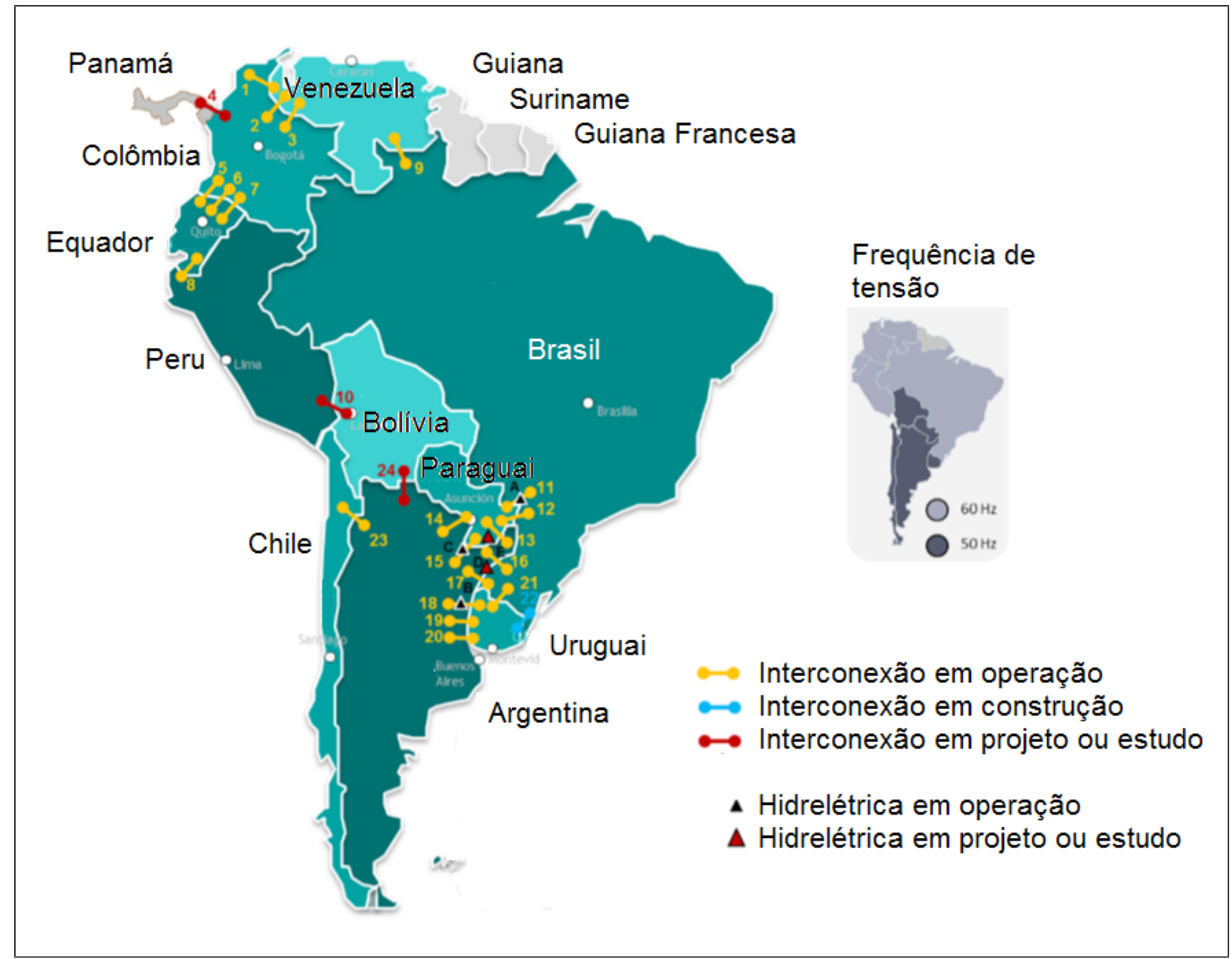

Fonte: CIER, 2013. 
A Tabela 2 apresenta os montantes resultantes de processos de exportação e importação realizados, em 2014, entre os países da América do Sul. A quantidade de energia é pequena e residual se comparada com o total consumido nos vários países. O total comercializado entre os países foi de 44,3 TWh, enquanto o consumo total em todos os países em 2014 foi de 1141 TWh. Ou seja, representa apenas 3,88 \%. Entretanto, grande parte desse montante envolveu o Paraguai como exportador de eletricidade para o Brasil e para a Argentina, ou seja, excluindo-se as exportações do Paraguai, fica evidente o baixo intercâmbio de eletricidade entre os países da região $(0,25 \%$ do total consumido). A título de comparação, na Europa esse valor chega a 10\% (PINTO, 2017).

\section{Tabela 2. Exportação e importação de eletricidade (TWh)} por países da América do Sul em 2014

\begin{tabular}{|c|c|c|c|}
\hline País & $\begin{array}{l}\text { Export. } \\
(\mathrm{TWh})\end{array}$ & $\begin{array}{l}\text { Import. } \\
\text { (TWh) }\end{array}$ & Observação (cifras em TWh) \\
\hline Argentina & 0,001 & 9,735 & $\begin{array}{l}\text { Importação do Paraguai }(8,461) \text {, Uruguai }(1,267) \text {, Brasil }(0,003) \\
\text { e Chile }(0,004) \text { e exportação para o Brasil }(0,001)\end{array}$ \\
\hline Brasil & 0,003 & 33,779 & $\begin{array}{l}\text { Importação do Paraguai }(32,939) \text {, Venezuela }(0,839) \text { e } \\
\text { Argentina }(0,001) \text { e exportação para a Argentina }(0,003)\end{array}$ \\
\hline Chile & 0,004 & 0 & Exportação para a Argentina $(0,004)$ \\
\hline Colômbia & 0,746 & 0,02 & $\begin{array}{l}\text { Importação do Equador }(0,02) \text { e exportação para o Equador } \\
(0,718) \text { e a Venezuela }(0,028)\end{array}$ \\
\hline Equador & 0,02 & 0,731 & $\begin{array}{l}\text { Importação da Colômbia }(0,718) \text { e Peru }(0,013) \text { e exportação } \\
\text { para a Colômbia }(0,02)\end{array}$ \\
\hline Paraguai & 41,4 & 0 & Exportação para a Argentina $(8,461)$ e o Brasil $(32,939)$ \\
\hline Peru & 0,013 & 0 & Exportação para o Equador $(0,013)$ \\
\hline Uruguai & 1,267 & 0 & Exportação para a Argentina $(1,267)$ \\
\hline Venezuela & 0,839 & 0,028 & Importação da Colômbia $(0,028)$ e exportação para o Brasil $(0,839)$ \\
\hline
\end{tabular}

Fonte: CIER, 2013. 


\section{Proposta de arquitetura institucional para integração do setor elétrico da América do Sul}

Em termos de arquitetura de governança, a estrutura do Brasil prevê a presença forte do Estado como planejador e tal característica é também encontrada em outros países da América do Sul (CAF, 2016). Para que haja uma integração funcional do setor elétrico continental é necessária uma estrutura regional com funções e atribuições semelhantes. A estrutura proposta neste trabalho, embasada em comercialização de energia e à luz das arquiteturas estudadas do Brasil (BALAGUER, 2011; POLLITT; MARSILIU, 2016; CASTRO, 2015; CEPAL, 2016; CIER, 2016; PINTO, 2017), visa contemplar as preocupações de planejamento dos governos nacionais e conter instituições de mercado para permitir que o intercâmbio de energia flua de forma eficiente por meio de negociações entre inúmeros agentes dos vários países.

Do ponto de vista físico e de possíveis interconexões, a Figura 4 mostra a rede elétrica brasileira onde podem ser identificadas as linhas de transmissão próximas à fronteira e que possibilitariam o desenvolvimento local (SCHERMA, 2016) . Seriam promovidas conexões e linhas de transmissão nas fronteiras e os mercados conectados de ambos os lados da fronteira seriam vistos como extensões dos respectivos subsistemas nacionais. Isto é, do ponto de vista brasileiro, o país vizinho seria uma extensão do subsistema brasileiro e do ponto de vista dos países vizinhos, o Brasil seria uma extensão de seu sistema elétrico. Poderia ocorrer também integração entre os subsistemas da Região Sul do Brasil, Uruguai e Nordeste da Argentina. Um mercado integrado poderia ser implementado entre a região Norte do Brasil, Bolívia e Peru. Outros processos de integração poderiam ocorrer entre os outros países da América do Sul. Há um intercâmbio grande de energia entre Paraguai, Brasil e Argentina por meio de acordos binacionais rígidos, não uma integração de mercados com diversas empresas. Uma integração deste tipo pode também ocorrer entre esses países à medida que os prazos dos acordos vigentes vençam e novos arranjos sejam interessantes mutuamente.

Dentro desse novo ambiente, muitas empresas surgiriam no setor elétrico sul-americano buscando oportunidades de negócios e algumas delas poderiam ser de fora da América do Sul. Empresas estatais e empresas privadas atuariam inicialmente como importadoras e exportadoras de energia elétrica. A importação e exportação de energia muitas vezes não se apresentam interessantes para as grandes empresas estatais nacionais por se tratarem de blocos pequenos de energia. 
Já as empresas menores de comercialização de energia, poderiam considerar essas atividades como oportunidades de negócios.

Nesse contexto, os aspectos regulatórios, operacionais e de comercialização de energia devem refletir equidade e transparência para todos os países participantes. Algumas questões importantes são regras de compra e venda de energia, regras de planejamento energético compartilhado e regras de interrupção de fornecimento transfronteiriço em momentos de dificuldades nacionais.

Na Figura 5, apresenta-se uma possível estrutura institucional do setor elétrico da América do Sul, de acordo com a metodologia proposta neste trabalho. Ela identifica com clareza as várias arenas em que um agente econômico tem que atuar e as organizações funcionais necessárias para viabilizar os detalhes operacionais. Um agente econômico pode ser uma empresa geradora de energia, um produtor independente, distribuidores de energia, comercializadores de energia, consumidor de energia etc. Esse agente interage com um conjunto de stakeholders em diversas situações, condições ou locais.

Figura 5. Possível estrutura para o sistema integrado dos mercados de eletricidade da América do Sul mostrando agentes e as arenas de governança.

0 foco é o aumento da comercialização de energia.

Ver texto para identificar as siglas

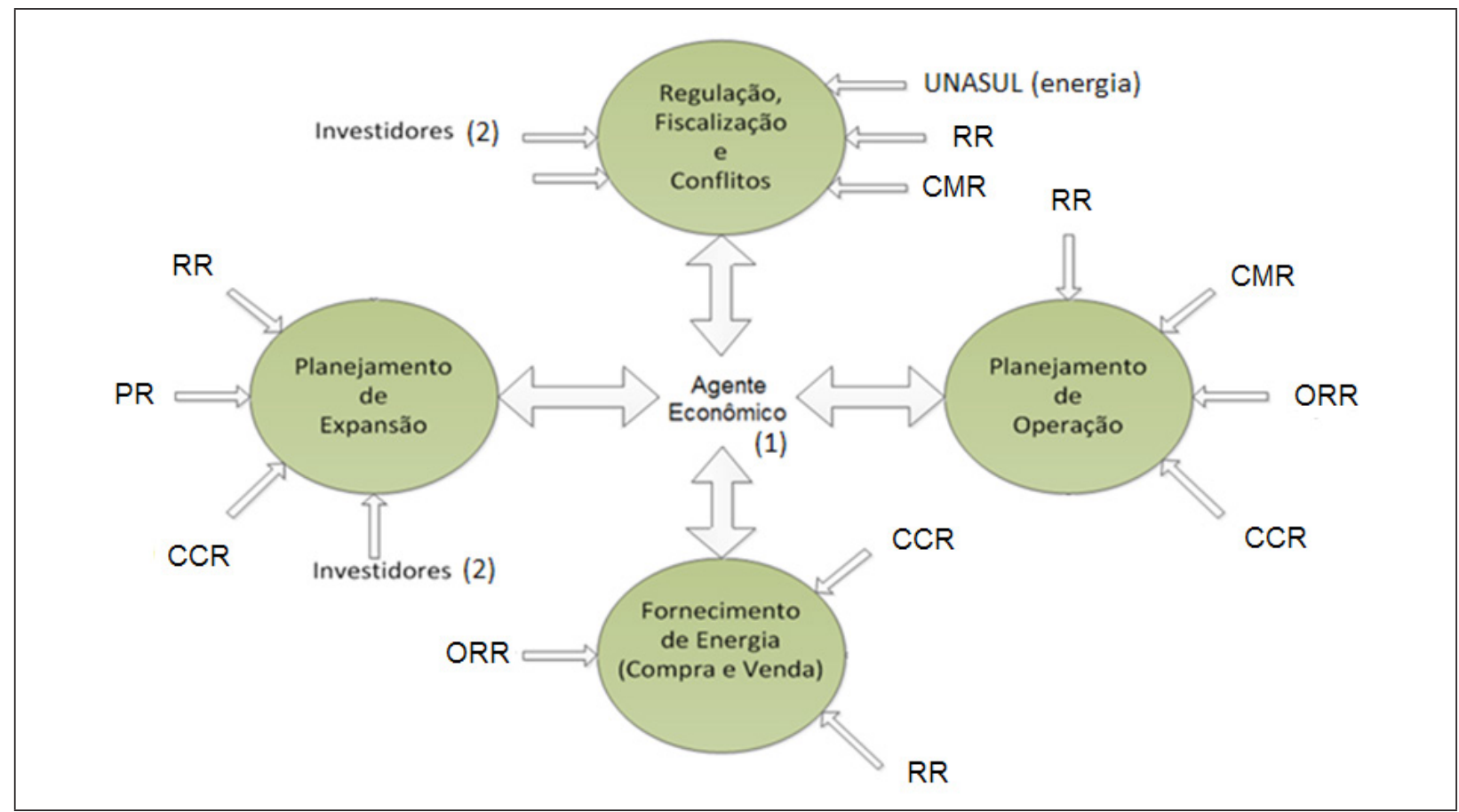

(1) Agentes econômicos: geradores, produtores independentes, distribuidores, comercializadores, consumidores livres ou cativos, importadores, etc.

(2) Investidores: bancos de investimento, agências de fomento, investidores privados, investidores públicos, etc.

Fonte: Autoria própria. 
Esses stakeholders podem ser as instituições regionais vinculadas ao processo de integração; outros agentes econômicos; participantes da sociedade organizada como governos, prefeituras, associações ou segmentos da sociedade; e investidores públicos ou privados, bancos, agências de fomento etc.

Conforme mostra a Figura 5, foram consideradas quatro arenas principais: arena de fornecimento de energia, onde se realiza as operações de compra e venda de energia; arena de planejamento da operação do sistema elétrico, onde se define como será o despacho de energia elétrica; arena de planejamento da expansão do sistema, onde se viabiliza novos investimentos e crescimento do sistema; e uma arena de regulação, fiscalização e de resolução de conflitos. Para atuar nessas arenas, foram também propostas organizações funcionais para representar os diferentes interesses dos stakeholders e agentes: Conselho de Monitoramento Regional (CMR), Regulador Regional (RR), Planejamento Regional (PR), Operador de Rede Regional (ORR) e Câmara de Comercialização Regional (CCR). Essas organizações funcionais seriam regionais, com membros dos países envolvidos. Inicialmente, seriam escritórios especializados que eventualmente poderiam evoluir para o status de instituições específicas de acordo com o volume das atividades envolvidas.

Essas organizações regionais devem ser as mais leves possíveis, visar operacionalizar e viabilizar a comercialização e despacho da energia e estariam subordinadas à UNASUL e/ou às respectivas agências reguladoras nacionais e ministérios com interesse nas questões. Um produtor independente (um comercializador ou um consumidor industrial, ou um membro da sociedade local) interagirá com esse sistema de arenas ao longo de suas atividades econômicas e questionamentos públicos ou privados.

Essas instituições regionais devem ser constituídas por especialistas indicados pelos respectivos governos nacionais em regime de rotatividade. Esses especialistas representariam os pontos de vista nacionais nas tratativas do sistema integrado de comercialização de energia elétrica. Essas instituições responderiam aos conselhos superiores de alto nível já existentes na América do Sul como, por exemplo, a UNASUL.

O Conselho de Monitoramento Regional seria responsável pelo monitoramento da política energética definida pelos países participantes para o intercâmbio de energia transfronteriço. Também seria responsável pela supervisão geral das ações das outras organizações. Nesse contexto, há grande interação com os governos nacionais para a convergência de interesses e com as demais organizações regionais. 
O Regulador Regional seria responsável pela realização das ações inerentes à harmonização regulatória, que pode ocorrer em etapas. Em uma fase inicial, sem a integração efetiva de mercados, os países e agentes participantes definem as regras comuns, sem intervenção nos respectivos modelos regulatórios de cada um. Em um modelo de mercados integrados, como o adotado pela União Europeia, a harmonização regulatória configura etapa fundamental para o sucesso da solução adotada e, nesse caso, cada país promove as alterações necessárias e em prazos factíveis definidos de comum acordo com o RR. O Planejamento Regional seria responsável pela coordenação de estudos de expansão e projeções. De certa forma, isso já ocorre com as propostas do COSIPLAN para o setor de energia elétrica, com projetos de expansão do setor elétrico, seja na geração, transmissão e/ou distribuição de energia elétrica. Essa organização teria uma atuação forte com o COSIPLAN e bancos de investimentos. O Operador de Rede Regional seria responsável pela realização de planejamento e programação da operação sul-americana, bem como pelo despacho de energia transfronteiriça. Questões, como a interrupção de fornecimento de energia elétrica, seriam operacionalizadas nessa organização, que teria grande interação com os operadores nacionais em razão da prioridade na manutenção de garantia de suprimento elétrico para os mercados nacionais. A Câmara de Comercialização Regional seria responsável pela administração e aplicação das regras de comercialização definidas pelo RR e pela garantia dos pagamentos e recebimentos dos vários agentes econômicos.

Na próxima seção, discutem-se as vantagens e limitações dessa proposta vis-à-vis ás barreiras apresentadas na introdução desse trabalho.

\section{Vantagens e limitações da proposta}

A premissa básica é que a segurança energética dos países do continente sul-americano pode ser garantida de forma eficiente e compartilhada com a contribuição dos vários países, isto é, a segurança energética pode ser garantida por energia oriunda de locais além das fronteiras de cada país. A experiência de integração do setor elétrico brasileiro, que apresenta uma economia de investimentos de $20 \%$, e de integração do sistema elétrico da União Europeia são evidências dessa possibilidade. 


\section{Perda de autonomia nacional}

A perda da autonomia nacional é uma questão importante para vários países e principalmente para o Brasil. A política externa brasileira evita ou apoia de forma comedida a criação de instituições regionais por diversas razões, porque não gostaria de limitar ações diplomáticas em arenas internacionais e de incorrer em custos extras na região por ser o país de maior porte econômico (SPEKTOR, 2010; CARVALHO; GONÇALVES, 2016; SARAIVA, 2013). Nesse caso específico do setor elétrico, as restrições de autonomia que mais incomodam os diversos países seriam regras de compra e venda de energia; regras de planejamento energético compartilhado e regras de possibilidade de interrupção no fornecimento em momentos de falta de energia no país. As regras de compra e venda de eletricidade seriam regras operacionais de um mercado integrado e administradas nas arenas de planejamento da operação e fornecimento de energia (compra e venda). Atualmente, todas essas ações são resolvidas em relações entre governos (DESIDERÁ NETO et al., 2014; SPEKTOR, 2010) e a comercialização de energia ocorre quando há excesso em um país e necessidade em outro. O estabelecimento de regras de comercialização no nível operacional não limitaria a autonomia dos países em arenas internacionais.

As regras de planejamento são consideradas muito importantes por todos os países do continente porque as cobranças da sociedade sobre um governo, causadas pela falta de fornecimento de eletricidade no país, são enormes. A estruturação da arena de planejamento da operação poderia prever regras de fornecimento durante períodos de alta disponibilidade de eletricidade e de interrupção do fornecimento em caso de escassez interna. Novamente, não haveria perdas de autonomia por parte dos países nessa questão fundamental, pois as regras seriam discutidas previamente e estabelecidas no nível operacional. Note-se que tal arena não existe na União Europeia, onde as decisões são oriundas de indicações do mercado. Aqui, ela foi introduzida justamente para acomodar possíveis intervenções dos governos nacionais.

As regras de interrupção de fornecimento de energia devem ser bem estabelecidas para evitar que acordos previamente firmados sejam desrespeitados. Os desentendimentos que ocorreram no passado, relativos à eletricidade e ao gás natural, entre Brasil e Argentina, Argentina e Chile e Brasil e Bolívia poderiam ser evitados. 


\section{Perda de capacidade de planejamento e de segurança energética}

Foi mencionado anteriormente que os governos nacionais não admitem correr o risco de deixar suas sociedades sem energia elétrica por razões políticas e, consequentemente, isso induz o desejo de participar efetivamente do planejamento energético. A segurança energética é considerada estratégica em todos os países. Outra razão que induz a presença dos governos no planejamento energético é a taxa elevada de crescimento do setor elétrico na América do Sul. A Figura 3 mostra que vários países têm taxas de crescimento acima de $4 \%$ ao ano, muito maior que a taxa de crescimento dos mercados europeu ou norte-americano de eletricidade, que tem sido negativa nos últimos 5 anos. Há uma percepção que crescimento assim tão elevado não possa ser atendido tempestivamente por um planejamento guiado apenas por sinais de mercado.

Uma terceira razão associada à atuação dos governos no planejamento energético pode ser considerada cultural. Trata-se da questão de planejamento centralizado numa estrutura top-down versus planejamento distribuído com a participação de várias organizações (MARIANO, 2014; NAKAGAWA; FAVARETO, 2012). Para acomodar tais preocupações de governos nacionais, a proposta tem uma presença forte nas várias organizações propostas e há organizações específicas de planejamento (PR) e de operação (ORR).

A estrutura da governança do setor elétrico integrado da América do Sul, se desejar-se que ela seja longeva, deve ter uma flexibilidade tal que permita que os vários governos, que mudam ao longo dos anos, possam realizar suas políticas energéticas de acordo com seus programas. Devem ter arquitetura e regras que permitam a intensificação das atividades de mercado quando essas forem de interesse dos vários governos e também a intensificação de iniciativas e ações do Estado, quando seus governos assim definirem como necessário.

Assim, de toda forma, para viabilizar a integração do setor elétrico na América do Sul parece ser necessário acomodar no planejamento energético sinais de mercado e a ação planejadora dos governos para, entre outras coisas, assegurar o fornecimento de energia para as respectivas sociedades. A dificuldade de se conseguir tal planejamento do setor elétrico no cotidiano, evitando riscos de suprimento devido a amarrações de acordos entre países, advém da ausência de instituições regionais (MARIANO, 2014). Uma arena de planejamento da expansão, com instituições regionais adequadas, poderia cuidar dos detalhes da expansão do setor e de fornecimento de energia. 
Sem essa base institucional, todas as ações recaem sobre as chancelarias e ministérios dos governos, que não conseguem resolver os detalhes (MARIANO, 2014). Uma vez estabelecidas essas regras, os processos aconteceriam sem a necessidade de atuação direta dos governos. Não haveria perdas de capacidade de planejar ou de garantir a segurança energética por parte dos países, porque as regras seriam discutidas previamente. Mesmos na ocorrência de conflitos, o desgaste nas relações entre os países seria diminuído, posto que câmaras de resolução de conflitos também fossem criadas.

\section{Esgotamento das reservas nacionais}

O esgotamento de reservas nacionais não é uma questão impeditiva para a integração do setor elétrico da América do Sul. Os amplos potenciais de energia primária hidráulica e eólica no continente tornam essa questão menor em comparação a regiões que contam apenas com recursos naturais não renováveis como fontes primárias de energia. Enfatizando a implantação de projetos a partir de energias renováveis e sustentáveis, a questão do esgotamento seria evitada.

\section{Assimetrias entre os países}

As principais questões ligadas às assimetrias são porte dos mercados dos diferentes países, porte das companhias dos diferentes países, grau de industrialização diferente dos países e diferentes níveis de competitividade de suas economias. Discutem-se abaixo alguns desses pontos, mas registra-se que, na maioria das vezes, tais assimetrias são recursos retóricos utilizados para justificar a falta de interesse, de grupos determinados nos países, em efetivamente viabilizar a integração (DESIDERÁ NETO et al., 2014; CASTRO et al., 2015).

A assimetria relacionada ao porte ou escala das economias é muito discutida, pois a economia brasileira é muito maior que as dos países vizinhos. Há uma percepção de que as empresas brasileiras acabariam por dominar todo o mercado integrado. Entretanto, uma solução para o pequeno porte das outras economias é a própria integração que dá acesso ao mercado integrado e permite ganhos de escala para suas empresas públicas ou privadas (DESIDERÁ NETO et al., 2014; KAS, 2016; MAYO, 2012). Esse problema ocorreu também na Europa, em relação aos mercados sub-regionais e aos dos grandes países continentais, como Alemanha, França, Reino Unido e Itália. Por exemplo, o mercado escandinavo promoveu, em um primeiro momento, uma intensa integração regional, buscando ganhar 
porte, para depois se integrar ao mercado energético do Norte da Alemanha e Holanda. Ocorreu, inclusive, a fusão de empresas, que ganharam maior escala para fazer frente à concorrência de empresas maiores de países vizinhos (POLLITT; MUSILIU, 2016).

\section{Atração de investimentos nacionais e internacionais}

O setor de eletricidade é uma indústria de rede em que as instalações são intensivas em capital e atravessam as fronteiras dos países. As regras de operação e comercialização devem ser comuns aos vários países, atravessar as fronteiras e vigorar durante 20 ou 30 anos para viabilizar a remuneração dos investidores (HALLACK, 2014). Há duas fontes primárias de recursos para investimento: público, provido pela ação dos Estados; e privado, provido pela iniciativa privada dos vários países sul-americanos e do exterior. Para ocorrer investimentos públicos é necessário o acerto entre governos e, atualmente, o grau de institucionalização existente no COSIPLAN já é suficiente para viabilizar investimentos decididos no nível de governos nacionais (MARIANO, 2014). Para ocorrer financiamentos e investimentos privados, é necessário um conjunto de regras que dê segurança a esses agentes. Verificam-se, entretanto, dificuldades para a atração de investimentos privados. As mais citadas são a falta de instituições para gestão de projetos, inadequação das formas de financiamento a partir de entes internacionais e falta de um conjunto harmonizado de regras de comercialização de longo prazo entre os países (DESIDERÁ NETO et al., 2014). Essa proposta contribui para viabilizar investimentos privados na região, pois um investidor, para tomar uma decisão, interagiria com as 4 arenas do sistema elétrico integrado.

\section{Modernização e ganhos de competitividade}

A integração do setor elétrico sul-americano pode contribuir para a modernização e avanço tecnológico do continente por meio de ações patrocinadas pelas iniciativas privada e pública. Contudo, a integração da América do Sul dificilmente levará seus países automaticamente a participar das cadeias produtivas globais de ponta simplesmente porque os países mais avançados do continente ainda não têm uma participação expressiva em tais cadeias. Entretanto, o investimento privado internacional (de fora da América do Sul) pode contribuir para esse objetivo por meio de difusão de tecnologia moderna, inovações de gestão e ganhos de competitividade de toda a sociedade. A experiência institucional adquirida com a 
integração pode ser estendida para outros setores econômicos dos diversos países, também contribuindo para a modernização (DESIDERÁ NETO et al., 2014).

\section{Maturidade institucional do continente}

Das avaliações anteriores ressalta-se a importância de se institucionalizar as várias arenas que caracterizam a governança necessária para se conseguir uma comercialização mais intensa de energia elétrica entre os países da América do Sul e obter otimização de recursos, eficiência econômica e desenvolvimento. Uma primeira pergunta a ser feita é se há, nos diversos países, condições ou maturidade institucional que permitam essa comercialização mais intensa da energia elétrica. A resposta é sim, em vários dos países. Os países com a presença mais marcante de instituições econômicas de mercado apresentam setores mais complexos de energia elétrica que se aproximam mais do modelo europeu. Atualmente, é o caso da Colômbia, Peru, Chile e Brasil. Nesses países, vários agentes atuam na geração, transmissão e distribuição de energia elétrica. Tecnicamente, esses países podem buscar implementar uma integração nos moldes europeus com maior facilidade. Países com políticas econômicas menos liberais e de maior ativismo estatal apresentam mercados de energia elétrica mais simples, mas com competição no setor de geração. Atualmente, esse é o caso da Argentina, Bolívia e Equador. E, finalmente, há países que tem seus sistemas elétricos totalmente verticalizados (Uruguai, Venezuela e Guiana).

Outro ponto que indica um ganho de maturidade na região para possibilitar a criação de instituições regionais de características mais operacionais, como as descritas neste trabalho, é o conjunto de edifícios institucionais já construídos (UNASUL, MERCOSUL, CAN etc.). Eles foram estabelecidos, não sofreram ameaças de retrocesso, mesmo em momentos de crise, e as reuniões entre chefes de Estado ocorrem frequentemente (DESIDERÁ NETO et al., 2014; SPEKTOR, 2010; TEIXEIRA, 2014).

\section{Conclusões}

Este trabalho considerou o problema da integração regional sul-americana por meio da comercialização de energia elétrica transfronteiriça. A metodologia adotada foi a do estabelecimento de regras, normas e arenas para o setor elétrico da América do Sul e a governança diplomática. Buscou-se viabilizar a comercialização 
e despacho de energia elétrica através da criação de instituições e estruturas de governança em níveis operacionais abaixo daquelas já existentes em níveis de governo. A preocupação foi viabilizar as atividades cotidianas envolvidas no processo de desenvolvimento de novos projetos de geração, transmissão e comercialização de energia elétrica, a integração física, técnica, comercial e principalmente a solução de conflitos das relações comerciais e de investimento.

Para operacionalizar essas arenas, foi identificada a necessidade de 5 organizações regionais para representar os diferentes interesses dos agentes econômicos, stakeholders e agentes dos vários países. Essas organizações teriam as funções de monitoramento, regulação e solução de conflitos, planejamento, operação da rede regional e de comercialização de eletricidade. Mostrou-se que tal arquitetura de instituições permitiria a geração e comercialização de energia elétrica por agentes de mercado dos países envolvidos e também acomodaria as ações de governo no planejamento da expansão do setor e na operação do sistema elétrico integrado.

Essa proposta poderia iniciar por meio da integração entre o Brasil e países vizinhos e se basear em energias renováveis e sustentáveis para evitar a exaustão de recursos energéticos. Os mercados conectados de ambos os lados da fronteira seriam vistos como extensões dos respectivos subsistemas nacionais. Projetos de geração de energia em ambos os lados da fronteira atenderiam os mercados dos dois países. Essa integração entre países vizinhos pode ser vista como um processo passo a passo, como aquele ocorrido na União Europeia.

A implementação de tal estrutura institucional requer liderança e envolve custos. O Brasil, embora tenha avançado bastante em suas ações no âmbito regional, ainda se apresenta avesso a assumir uma posição de liderança na América do Sul. Contudo, para as relações sul-americanas atuais evoluírem é necessário um grau maior de sofisticação das instituições regionais. Os projetos que envolvem ações multilaterais na área de infraestrutura não são desenvolvidos porque a instância de alto nível já estabelecida é insuficiente para atividades cotidianas. É preciso avançar e começar a institucionalização das arenas técnicas, conforme ocorreu no CAN e no MERCOSUL, que criaram instituições equivalentes para cuidar das relações comerciais entre os diversos países.

O Brasil deveria considerar liderar esse processo e arcar com uma fração importante dos custos para a implantação e manutenção dessas instituições, isto é, atuar como um paymaster parcial para iniciar relações bilaterais de comercialização de eletricidade com os países vizinhos. 


\section{Referências}

BALAGUER, J. Cross-border integration in the European electricity market. Evidence from the pricing behavior of Norwegian and Swiss exporter. Energy Policy, v. 39, 2011, p. 4703-4712.

CAF. Energia: Uma visión sobre los retos y oportunidades em América Latina y El Caribe - Integracíon Energética - Documento de trabajo - Borrador para discusión y análisis. Corporación Andina de Fomento. Disponível em: < http://scioteca.caf. com/handle/123456789/608. Acesso em: 20/07/2016.

CARVALHO, P. N.; GONÇALVES, F. C. N. I. O Brasil como potência regional: uma análise da sua liderança na América do Sul no início do século XXI. Carta Internacional, V. 11, 2016, p. 222-248.

CASTRO, J. N. et al. Integração elétrica internacional do Brasil: Antecedentes, situação atual e perspectivas. Texto de Discussão do Setor Elétrico n ${ }^{\circ}$ 64. GESEL - Grupo de Estudos do Setor Elétrico - UFRJ, 2015. Disponível em: < http://www.gesel.ie.ufrj.br/ app/webroot/files/publications/52_TDSE64.pdf > . Acesso em: 10 de setembro de 2015.

CEPAL. Integración eléctrica em América Latina: antecedentes, realidades y caminhos por recorrer. Coordinator Beno Ruchanski, 2013, Comissión Económica para América latina y Caribe. Disponível em: < http://www.cepal.org/pt-br/node/20658 > Acesso em: 30 de março de 2016.

CIER. Síntesis Informativa Energética de los Países de la CIER. Información del sector energético en países de América del Sur, América Central y El Caribe. Comisión de Integración Energética Regional, 2013. Disponível em: < http://www.cier.org/es-uy/ Lists/EstadisticasLD/Sintesis2013.pdf > . Acesso em: 28 de abril 2018.

DESIDERÁ NETO, W. A.; MARIANO, M. P.; PADULA, R.; HALLACK, M. C. M.; BARROS, P. S. Relações do Brasil com a América do Sul após a Guerra fria: política externa, integração, segurança e energia. In DESIDERÁ NETO, W. A. O Brasil e novas dimensões da integração regional, Instituto de Pesquisa Econômica Aplicada, IPEA, 2014.

EIA. International Energy Statistics. US Energy Information Administration. Disponível em: < https://www.eia.gov/beta/international/data/browser > , 2016. Acesso em: 20/02/2016.

GONÇALVES A. O Conceito de governança. In: XV Congresso Nacional do CONPEDI/UEA. Manaus, AM, Anais de Congresso, 2006. Disponível em: < http://www.conpedi. org. br/manaus/arquivos/Anais/Alcindo\%20Goncalves.pdf > . Acesso em: 10/03/ 2016. 
HALLACK, M. C. M. A integração da indústria de gás natural na América do Sul: desafios institucionais no desenvolvimento de infraestruturas de conexão. In DESIDERÁ NETO, W. A. O Brasil e novas dimensões da integração regional. Instituto de Pesquisa Econômica Aplicada, IPEA, 2014.

HERZ, M.; HOFFMANN, A. R.; TABAK, J. Organizações internacionais: história e práticas. Capítulo 5, Integração Regional. Rio de Janeiro, RJ: Elsevier Editora, 2015 a.

HERZ, M.; HOFFMANN, A. R.; TABAK, J. Organizações internacionais: história e práticas. Capítulo 2, Contribuições teóricas para o estudo de organizações. Rio de Janeiro, RJ: Elsevier Editora, 2015b.

HERZ, M.; HOFFMANN, A. R.; TABAK, J. Organizações internacionais: história e práticas. Capítulo 4, Governança global e as agências especializadas. Rio de Janeiro, RJ: Elsevier Editora, 2015c.

KAS. Integração Energética Regional: Desafios Geopolíticos e Climáticos. Organizadores: Fundação Konrad Adenauer. Programa Regional Segurança energética e Mudanças Climática na América Latina. Fundação Konrad Adenauer e Centro Brasileiro de Relações Internacionais - CEBRI. Disponível em: < http://www.kas.de/energieklima-lateinamerika/pt/publications/43761/>. Acesso em: 30 de novembro de 2016.

MARIANO, M. P. O papel do Brasil na 'integração da infraestrutura da América do Sul: limites institucionais e possibilidades de mudança. In DESIDERÁ NETO, W. A. O Brasil e novas dimensões da integração regional, Instituto de Pesquisa Econômica Aplicada, IPEA, 2014.

MAYO, R. Mercados de eletricidade. Rio de Janeiro: Synergia, 2012.

MOREIRA, J. M. L., CESARETTI, M. A., CARAJILESCOV, P. , MAIORINO, J. R. Sustainability deterioration of electricity generation in Brazil. Energy Policy, v. 87, 2015, p. 334-346.

MOREIRA, J. M. L.; PINTO, R. T. S. Institucionalizar para avançar a integração de mercados de eletricidade na América do Sul. In MOREIRA et al. Questões sobre Energia, Capítulo 3. Ed. Interciência, Rio de Janeiro, 2017.

NAKAGAWA, L.; FAVARETO, A. S. Governança e mercados na elaboração de políticas socioambientais em iniciativas multi-stakeholder: a emergência da governança não estatal. In: VI Encontro Nacional da ANPPAS, 18 a 21 de setembro de 2012, Belém, PA.

ONS. Mapa do sistema interligado nacional (SIN) do Brasil. Operador Nacional do Sistema Elétrico. Disponível em < http://www.ons.org.br/conheca_sistema /mapas_sin. aspx > . Acesso em: 26/12/2016. 
ONS. Acompanhamento mensal dos intercâmbios internacionais - janeiro de 2016. Acervo Digital ONS. Relatório ONS RE 4/011/2016. Disponível em < http://www. ons.org.br/download/resultados_operacao/acompanhamento_mensal_intercambios_ internacionais/relatorio_intercambio_internacional_201201.pdf > . Acesso em: 18/01/2016a.

PADULA, R. Da IIRSA ao COSIPLAN: a integração da infraestrutura na América do Sul nos anos 2000e suas perspectivas de mudança. In DESIDERÁ NETO, W.A. O Brasil e novas dimensões da integração regional, Instituto de Pesquisa Econômica Aplicada, IPEA, 2014.

PINTO, R. T. S. Integração dos mercados de eletricidade da América do Sul por meio da comercialização de energia elétrica. Dissertação de Mestrado. Santo André, SP: Universidade Federal do ABC, 2017.

POLLITT, G. M.; MUSILIU, O. O. The promotion of regional integration of electricity markets: Lessons for developing countries. Energy Policy, v. 88, 2016, p. 628-638.

PSR. Latin American Energy Integration - Opportunities and challenges, APEX. 2011. Disponível em < http://www.apex2011conference.com > , 2012. Acesso em: 30/07/2015.

SARAIVA, M. G. Novas abordagens pra análise dos processos de integração na América do Sul: o caso brasileiro. Carta Internacional, v. 8, 2013, p. 3-21.

SCHERMA, M. A. Rumo à cooperação e ao desenvolvimento: as políticas brasileiras para a faixa de fronteira. Carta Internacional, v. 11, 2016, p. 32-55.

SOARES, R. T.; MOREIRA, J. M. L. A questão do modelo de integração energética da América do Sul - foco na comercialização de energia elétrica. In: VIII Congresso Brasileiro de Planejamento Energético, 12-15 de agosto de 2012. Curitiba, PR. Disponível em < http://sbpe.org.br/viii-cbpe/ > . Acesso em: 25/08/2017.

SPEKTOR, M. Ideias de ativismo regional: a transformação das leituras brasileiras da região. Revista Brasileira de Política Internacional, v. 53, 2010, p. 24-44.

TEIXEIRA, C. G. P. Uma política para o continente - reinterpretando a Doutrina Monroe. Revista Brasileira de Política Internacional, v. 57, 2014, p. 115-132. 